Open Access

\title{
Disease-modifying effects of phosphocitrate and phosphocitrate- $\beta$-ethyl ester on partial meniscectomy-induced osteoarthritis
}

Yubo Sun ${ }^{1 *}$ (D, Nikkole Haines ${ }^{1}$, Andrea Roberts ${ }^{1}$, Michael Ruffolo ${ }^{1}$, David R. Mauerhan ${ }^{1}$, Kim L. Mihalko ${ }^{2}$, Jane Ingram', Michael Cox ${ }^{1}$ and Edward N. Hanley $\mathrm{Jr}^{1}$

\begin{abstract}
Background: It is believed that phosphocitrate (PC) exerts its disease-modifying effects on osteoarthritis $(\mathrm{OA})$ by inhibiting the formation of crystals. However, recent findings suggest that PC exerts its disease-modifying effect, at least in part, through a crystal-independent action. This study sought to examine the disease-modifying effects of PC and its analogue PC- $\beta$-ethyl ester (PC-E) on partial meniscectomy-induced OA and the structure-activity relationship.

Methods: Calcification- and proliferation-inhibitory activities were examined in OA fibroblast-like synoviocytes (FLSs) culture. Disease-modifying effects were examined using Hartley guinea pigs undergoing partial meniscectomy.

Cartilage degeneration was examined with Indian ink, safranin-O, and picrosirius red. Levels of matrix metalloproteinase-13 (MMP-13), ADAM metallopeptidase with thrombospondin type 1 motif 5 (ADAMTS5), chemokine (C-C motif) ligand 5 (CCL5), and cyclooxygenase-2 (Cox-2) were examined with immunostaining. The effects of PC-E and PC on gene expressions in OA FLSs were examined with microarray. Results are expressed as mean \pm standard deviation and analyzed using Student's $t$ test or Wilcoxon rank sum test.

Results: PC-E was slightly less powerful than PC as a calcification inhibitor but as powerful as PC in the inhibition of OA FLSs proliferation. PC significantly inhibited cartilage degeneration in the partial meniscectomied right knee. PC-E was less powerful than PC as a disease-modifying drug, especially in the inhibition of cartilage degeneration in the non-operated left knee. PC significantly reduced the levels of ADAMTS5, MMP-13 and CCL5, whereas PC-E reduced the levels of ADAMTS5 and CCL5. Microarray analyses revealed that PC-E failed to downregulate the expression of many PC-downregulated genes classified in angiogenesis and inflammatory response.

Conclusions: $\mathrm{PC}$ is a disease-modifying drug for posttraumatic OA therapy. PC exerts its disease-modifying effect through two independent actions: inhibiting pathological calcification and modulating the expression of many genes implicated in OA. The $\beta$-carboxyl group of PC plays an important role in the inhibition of cartilage degeneration, little role in the inhibition of FLSs proliferation, and a moderate role in the inhibition of FLSs-mediated calcification.
\end{abstract}

Keywords: Calcification, Crystals, Osteoarthritis, Phosphocitrate, MMP-13, ADAMTS5, CCL-5

\footnotetext{
* Correspondence: yubo.sun@carolinashealthcare.org

'Department of Orthopedic Surgery, Carolinas Medical Center, PO Box 32861,

Charlotte, NC 28232, USA

Full list of author information is available at the end of the article
}

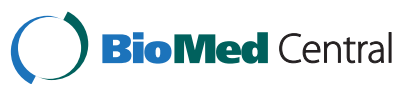

(c) 2015 Sun et al. Open Access This article is distributed under the terms of the Creative Commons Attribution 4.0 International License (http://creativecommons.org/licenses/by/4.0/), which permits unrestricted use, distribution, and reproduction in any medium, provided you give appropriate credit to the original author(s) and the source, provide a link to the Creative Commons license, and indicate if changes were made. The Creative Commons Public Domain Dedication waiver (http://creativecommons.org/publicdomain/zero/1.0/) applies to the data made available in this article, unless otherwise stated. 


\section{Background}

Osteoarthritis (OA) is a heterogeneous and multifactorial degenerative joint disease characterized by gradual loss of articular cartilage, formation of osteophytes, and synovial inflammation. Current non-surgical treatments for OA, such as non-steroid anti-inflammatory drugs and steroid injections, only relieves pain, inflammation, and effusion. There is a need for the development of disease-modifying drugs that can not only relieve pain and inflammation, but also inhibit cartilage degeneration. The lack of progress in the development of disease-modifying drugs is largely due to our limited understanding of the pathogenesis of OA and insufficient knowledge regarding the molecular targets for therapeutic intervention.

The biochemical events involved in OA are poorly understood. Many extracellular matrix degrading enzymes and inflammatory cytokines, including matrix metollproteinase-13 (MMP-13), ADAM metallopeptidase with thrombospondin type 1 motif 5 (ADAMTS5), interleukin-1 (IL-1), and cyclooxygenase-2 (Cox-2) have been implicated in OA [1-3]. Pathological calcification has also been implicated. Basic calcium phosphate crystals and calcium pyrophosphate dihydrate crystals are the two most common articular calcium-containing crystals. The presence of these crystals within the knee joints of end-stage OA patients is well recognized [4-9]. Injection of these crystals into the knee joints of dogs and mice induce a severe inflammatory response $[10,11]$. These crystals also induced cell mitogenesis and stimulated the production of matrix metalloproteinases (MMPs), nitric oxide, and inflammatory cytokines [12-15], suggesting that crystals may play a role in the development or progression of OA.

Phosphocitrate (PC) is a naturally occurring small molecule originally identified in rat liver mitochondrial extract [16]. Since its original identification, PC has been shown to be a powerful calcification inhibitor $[17,18]$. PC prevented soft tissue calcification and didn't produce any significant toxic side effect in rats in doses up to $150 \mu \mathrm{mol} / \mathrm{kg} /$ day [19]. In addition, PC inhibited crystalinduced mitogenesis, expression of MMPs, and cell death [20-22]. Based on these findings, a hypothesis that $\mathrm{PC}$ is a disease-modifying drug for calcification-induced OA therapy was postulated [23]. A subsequent study demonstrated that PC inhibited meniscal calcification, and that a decrease in meniscal calcification was accompanied with reduced cartilage degeneration in Hartley guinea pigs (calcification-induced OA), but had no significant effect on cartilage degeneration in partial meniscectomy-induced OA in rabbit (posttraumatic OA or non-calcification induced OA) [24]. The investigators concluded that $\mathrm{PC}$ is a disease-modifying drug for calcification-induced OA therapy but not for non-calcification-induced OA. It was believed that PC exerted its OA disease-modifying activity by inhibiting the formation of articular calcium crystals and the detrimental interaction between these crystals and joint cells (crystal-dependent action) [23, 24]. Although this theory was well received at the time, doubt emerged upon the findings that bisphosphonates, which were potent calcification inhibitors $[25,26]$, failed to inhibit cartilage degeneration in animal models of OA, including Hartley guinea pig model of calcification-induced OA $[27,28]$.

We recently found that PC downregulated the expression of many genes classified in cell proliferation, angiogenesis, and inflammatory response, while upregulating the expressions of many genes classified in skeletal system development in the absence of calcium crystals [29-31]. These newer findings suggest that crystal-dependent action of $\mathrm{PC}$ may not be a sole action underlying the $\mathrm{OA}$ disease-modifying effect of PC. It is likely that PC exerts its OA disease-modifying activity through two independent actions: i) inhibiting the formation of crystals and crystal-induced expressions of MMPs (a crystaldependent action), and ii) modulating the expressions of genes implicated in OA (a crystal-independent action).

PC- $\beta$-ethyl ester (PC-E) is a PC analogue where a $\beta$ carboxyl group is replaced by an ethyl ester group (Fig. 1). We are interested in PC-E not only because compared to PC, PC-E has less negative charges, therefore it may be more easily absorbed in the intestine if administered through the oral route, but also because novel new PC analogues may be prepared by linking other active group(s) to this carboxyl group. In this study, we sought to examine disease-modifying activity of PC and PC-E on posttraumatic $\mathrm{OA}$ and investigate the structure-activity relationship. The results of this study may not only provide information

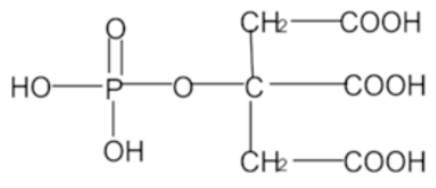

PC

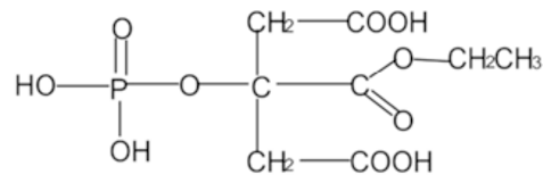

PC-E

Fig. 1 Molecular structures of $P C$ and $P C-E$ 
valuable for the design and development of new PC analogues as disease-modifying drug for OA therapy, but also for a better understanding of pathogenesis of OA and the molecular mechanism underlying the disease-modifying activity of PC.

\section{Methods}

Dulbecco's minimum essential medium (DMEM), fetal bovine serum, stock antibiotic/antimycotic mixture were obtained from Invitrogen (Carlsbad, CA). ${ }^{45} \mathrm{Cal}-$ cium was obtained from Perkin-Elmer (Boston, MA). Antibody specific to MMP-13 (Lifespan Biosciences, Seattle, WA), ADAMTS5 (Santa Cruz Biotechnology, Dallas, TX), Cox-2 (Santa Cruz Biotechnology, Dallas, TX), and CCL-5 (Bioss, Woburn, MA) were obtained from the commercial sources indicated. Safranin-O, fast green, picrosirius red, and alcian blue were obtained from Polysciences (Warrington, PA). PC and PC-E were prepared according to the method described [32]. All other chemicals were obtained from Sigma-Aldrich (St. Louis, MO).

\section{Calcification assay}

OA fibroblast-like synoviocytes (FLSs), similar to OA chondrocytes, play a role in the formation of articular crystal $[9,33,34]$. To compare the calcificationinhibitory activity of PC and PC-E, we performed an ATP-induced calcification assay using telomerase immortalized human OA fibroblast-like synoviocytes (FLSs), hTERT-OA 13A FLSs [9]. Briefly, hTERT-OA 13A FLSs were plated in a 24 well cluster plate at $95 \%$ confluence. On the second day, DMEM with $10 \%$ serum was changed to DMEM containing $0.5 \%$ serum. On the third day, after cells became quiescent, DMEM containing $1 \mathrm{mM}$ ATP and trace-labeled with $1 \mu \mathrm{Ci} / \mathrm{ml}{ }^{45} \mathrm{cal}-$ cium was added. Immediately, increasing amounts of PC, PC-E, or citrate were added into the wells. Fortyeight hours later, cells were washed with cold Hank's balanced salt solution five times and lysed with $0.1 \mathrm{~N}$ $\mathrm{NaOH}$. Radioactivity of lysate in each well was quantified using liquid scintigraphy. Calcification-inhibitory activity of disodium ethane-1-hydroxy-1, 1-diphosphonate (EHDP) was also examined. Results were presented as the mean \pm SD of five independent experiments.

\section{Proliferation assay}

Proliferation-inhibitory activities of PC-E and PC were examined as described [29]. Briefly, hTERT-OA 13A FLSs $\left(4 \times 10^{4}\right)$ were plated in six well cluster plates. On the second day, DMEM containing $10 \%$ serum and PC$\mathrm{E}(0.5 \mathrm{mM})$ or $\mathrm{PC}(0.5 \mathrm{mM})$ was added into the top three wells. DMEM containing $10 \%$ serum without PC$\mathrm{E}$ or PC was added into the bottom three wells as a control. DMEM was changed every three days until the cells in the bottom wells reached $85 \%$ confluence (cultured for about 12 to 14 days). All cells were then harvested and the cell number in each well was counted. Results were presented as the mean \pm SD of three independent experiments.

\section{Experimental animals}

This study was performed according to the guidelines set forth by the Institutional Animal Care \& Use Committee of Carolinas Medical Center, which approved the animal protocol. Male Hartley guinea pigs at three weeks of age were obtained from Charles River Laboratories (Wilmington, MA) and individually housed in $29 \times 21 \times 10$ inch solid bottom cages. Guinea Pig Chow (No. 5025; Ralston Purina, Richmond, Indiana) and water were available ad libitum. The first group of guinea pigs $(n=5)$ received intraperitoneal injection of PC $(40 \mathrm{mg} / \mathrm{kg})$ twice per week, second group $(n=5)$ received PC-E $(40 \mathrm{mg} / \mathrm{kg})$ and the last group $(n=5)$ received physiological saline. Two months later, partial medial meniscectomy was performed on the right knee of all guinea pigs to induce posttraumatic OA. A week after the surgery, injection of PC, PC-E, or saline was resumed. Five months later, these guinea pigs were euthanized by the administration of Euthasol (Virbac Animal Health, Ft. Worth, Texas). Hind limbs were collected, fixed in $10 \%$ formalin, and transferred to $70 \%$ ethanol until use. Structural changes in the articular cartilage of Hartley guinea pigs were not observed until three months of age [35], therefore pretreatment of the young guinea pigs with PC or PC-E for two months before partial meniscectomy surgery will not result in detectable structural changes in the articular cartilage.

Radiographic, microscopic, and histological examinations Radiographs of knee joints were obtained with a digital radiography system (piXaray 100, Bioptics Inc., Tucson, AZ). After dissection of the knee joints, radiographs of medial meniscus were obtained. All tibia plateaus were first stained with Indian ink as described [36]. The tibia plateaus were then decalcified in Cal-Ex II solution (Fisher Scientific, Fairlawn, NJ) and cut coronally in the center to produce two equal portions. The posterior portion was embedded in paraffin and sectioned with a Leica RM2025 microtome (Nussloch, Germany) to obtain $4 \mu \mathrm{m}$ sections. Three non-consecutive sets of sections (three consecutive sections in each set) obtained at $400 \mu \mathrm{m}$ intervals were stained with safranin-O and counter stained with fast green. These sections (nine sections for each cartilage specimen) were graded according to standard Mankin criteria with minor modifications [37]. Two sections in each cartilage specimens were also stained with picrosirius red and counter stained with alcian blue. 


\section{Cartilage thickness}

Central portion of safranin-stained sections (the most degenerative area) was photographed and the area of cartilage (same length for each section) was measured using the measuring tool in Adobe acrobat software (San Jose, CA). Briefly, the image file was opened with Adobe acrobat and the cartilage was traced continuously with the "pen" in the measuring tool along the irregular surface of the articular cartilage (numerous very short straight lines were connected together to form an irregular line) and the border between cartilage and subchondral bone. After tracing the cartilage was finished, the area was automatically calculated. Cartilage thickness is obtained by dividing the area with the length of the cartilage measured.

\section{Immunohistochemistry}

Two sections in each tibia plateau were deparaffinized with xylene and rehydrated with graded ethanol. Endogenous peroxidase activity was blocked by incubation with deionized water containing $3 \% \mathrm{H}_{2} \mathrm{O}_{2}$ for five minutes. Non-specific binding was blocked by incubation with $100 \mu \mathrm{l}$ of $10 \%$ normal horse serum diluted in base solution (4 \% BSA and $5 \%$ non-fat dry milk in PBS) for $20 \mathrm{~min}$. These sections were incubated with primary antibodies (1:100 dilution) for one hour, followed with secondary reagent for $30 \mathrm{~min}$ (Immpress reagent kit, Vector, Inc., Burlingame, CA). Negative control was performed using mouse IgG. Slides were rinsed in phosphate buffered saline three times and visualized with 3 , 3 '-diaminobenzidin. Slides were counterstained with light green, dehydrated and mounted with resinous mounting media. These slides were graded on a scale of $0-4$, where $0=$ very weak staining; $1=$ weak staining; $2=$ moderate staining; $3=$ strong staining; $4=$ very strong staining as described [38].

\section{Microarray}

Briefly, hTERT-OA 13A FLSs [9] were plated in two $100 \mathrm{~mm}$ plates at $90 \%$ confluence. On the second day, medium was changed to medium containing $1 \%$ serum. On the third day, medium containing $1 \%$ serum and PC-E $(0.6 \mathrm{mM})$ was added to a plate, and medium containing $1 \%$ serum but without PC-E was added to the other plate. Twenty-four hour later, total RNA was extracted using Trizol reagent (Invitrogen, Carlsbad, CA) and purified using Oligotex kit (Qiagen, Valencia, CA). These RNA samples were used for microarray as described [29]. Microarray analysis of PC on gene expressions has been performed previously [29].

\section{Statistical analyses}

Results of calcification assay, proliferation assay, and cartilage thickness measurements (variables measured on continuous interval) are presented as the mean $\pm \mathrm{SD}$. The differences between the results in 2 groups were analyzed using Student's $t$ Test. Scores of histological staining and immunostaining (variables presented as ordinal data) were presented as the mean $\pm \mathrm{SD}$. The differences between the scores in two groups were analyzed using Wilcoxon rank sum test. Statistical analysis was performed using the statistical analysis tool in the Sigma Plot software, version 12 (Systat Software, Inc., San Jose, CA).

\section{Results}

\section{Calcification- and proliferation-inhibitory activities}

PC, PC-E, and EHDP, but not citrate, inhibited ATPinduced calcium deposition in a dose dependent manner (Fig. 2a). PC is the most potent calcification inhibitor, with PC-E being $19 \%$ and EHDP being $13 \%$ less powerful than PC in the inhibition of OA FLSs-mediated calcium deposition at the concentration of $0.25 \mathrm{mM}(p<0.01)$. PC-E, similar to PC [29], also inhibited the proliferation of human OA FLSs (Fig. 2b). There were about $66 \%$ and $64 \%$ fewer human OA FLSs in the PC and PC-E treated wells, respectively, compared to controls $(p<0.01)$. PC and PC-E had no effect on cell viability up to the concentration of $10 \mathrm{mM}$ whereas EHDP caused cell death when its concentration was higher than $1.5 \mathrm{mM}$ (not shown).
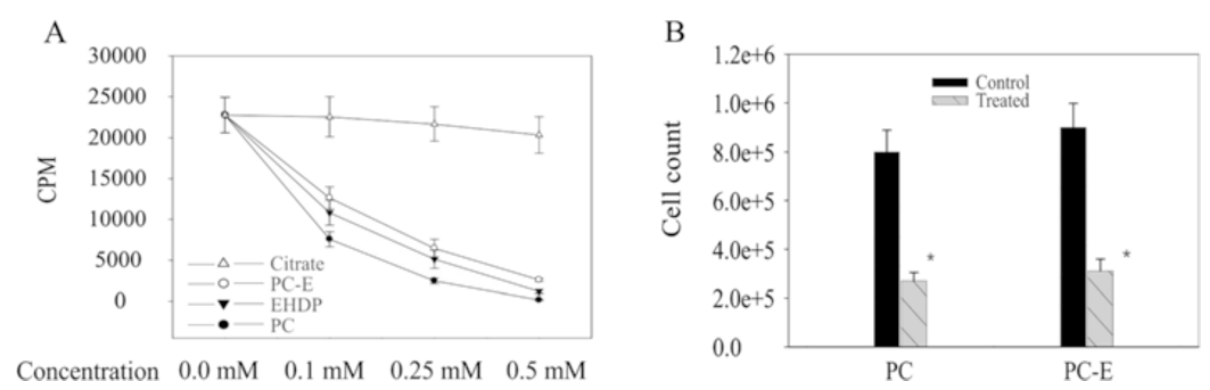

Fig. 2 Calcification- and proliferation-inhibitory activities. a PC, PC-E, and EHDP inhibit OA FLSs-mediated calcification. CPM (count per minute) in control, PC-E, PC and EHDP treated cells are 22,784 ( $\pm 2,156), 6,452( \pm 1,095), 2,466( \pm 352)$, and 5,124 $( \pm 1114)$, respectively, at the concentration of $0.25 \mathrm{mM}$. b PC and PC-E inhibit OA FLSs proliferation. Cell numbers in control and PC treated wells are 845,236 $( \pm 89,521)$ and 285,706 $( \pm 34,132)$. Cell numbers in control and PC-E treated wells are 924,484 $( \pm 98,718)$ and $331,096( \pm 48,694) .{ }^{*}=p<0.01$, versus control 


\section{Radiographic examinations}

Representative radiographs of the knee joints and medial menisci were provided in Fig. 3. As expected, calcified medial meniscus was observed in the non-operated left knee, but not in the meniscectomied right knee (Fig. 3a). Meniscal calcification predominantly occurred in the anterior horn of the medial meniscus (Fig. 3b). The severely calcified anterior horn of the medial meniscus was absent in the meniscectomied right knee. As shown in Fig. 3a, meniscus in the non-operated left knee of PC and PC-E treated guinea pigs were slightly less calcified compared to untreated guinea pigs, indicating that $\mathrm{PC}$ and PC-E reduced meniscal calcification. However, meniscal calcification in $\mathrm{PC}$ and $\mathrm{PC}-\mathrm{E}$ treated guinea pigs appeared similar. No signs of cartilage calcification were observed.

\section{Microscopic examinations}

Indian ink staining was used to examine the tibia plateaus of all guinea pigs. Representative Indian ink stained tibia plateaus are provided in Fig. 4. As shown, cartilage damage, visualized with the help of Indian ink, spanned a larger area in the medial tibia plateaus of the meniscectomied right knee than the cartilage damage in the medial tibia plateaus of the non-operated left knee (Fig. 4a). In the non-operated left knee, cartilage damage was confined in the central area of the medial tibia plateau (Green arrow) whereas in the meniscectomied right knee, cartilage damage was not only present in the central area (Green arrow) but also present in the peripheral area that was originally covered with meniscus (Red arrow). These results demonstrated that meniscal injury and joint instability resulted in increased cartilage degeneration, especially cartilage degeneration in the peripheral area, which was not observed in the non-operated left knee. As shown in Fig. 4b and c, there was less cartilage damage in the medial tibia plateau of the meniscectomied right knee, especially in the peripheral area, in PC and PC-E treated guinea pigs compared to untreated controls, indicating that PC and PC-E inhibited cartilage degeneration induced by meniscal injury and joint instability. There was also less cartilage damage in the medial tibia plateau of the non-operated left knee in PC and PC-E treated guinea pigs compared to untreated controls.

\section{Histological examinations}

Representative three non-consecutive safranin-O stained sections from the meniscectomied right knee in untreated and PC treated guinea pigs were provided in Fig. 5. Consistent with Indian ink staining, safranin-O staining revealed that severe cartilage damage occurred in both the central and peripheral areas of medial tibia plateau in

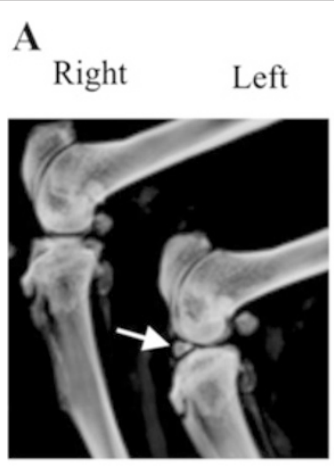

Untreated

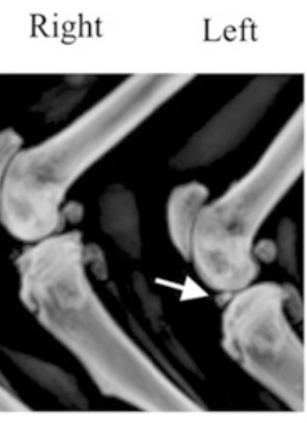

PC-treated

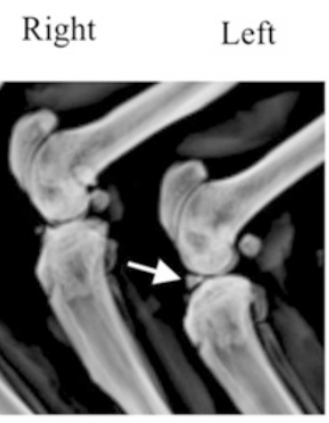

PC-E-treated

B

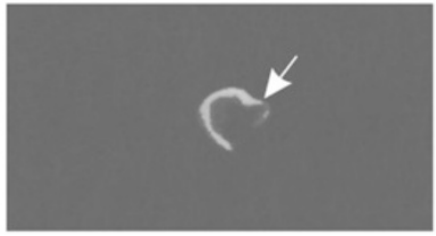

Right knee medial meniscus

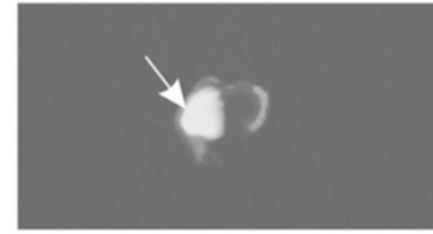

Left knee medial meniscus

Fig. 3 Radiographs of knees and medial menisci. a Representative radiographs of meniscectomied right knee and non-operated left knee of untreated, PC-treated, and PC-E treated guinea pigs. Calcified medial menisci are indicated by arrows. $\mathbf{b}$ Radiographs of the meniscectomied right knee medial meniscus and the non-operated left knee medial meniscus of an untreated guinea pig. Severely calcified anterior horn of the medial meniscus (arrow) is present in the left knee, but not in the right knee 

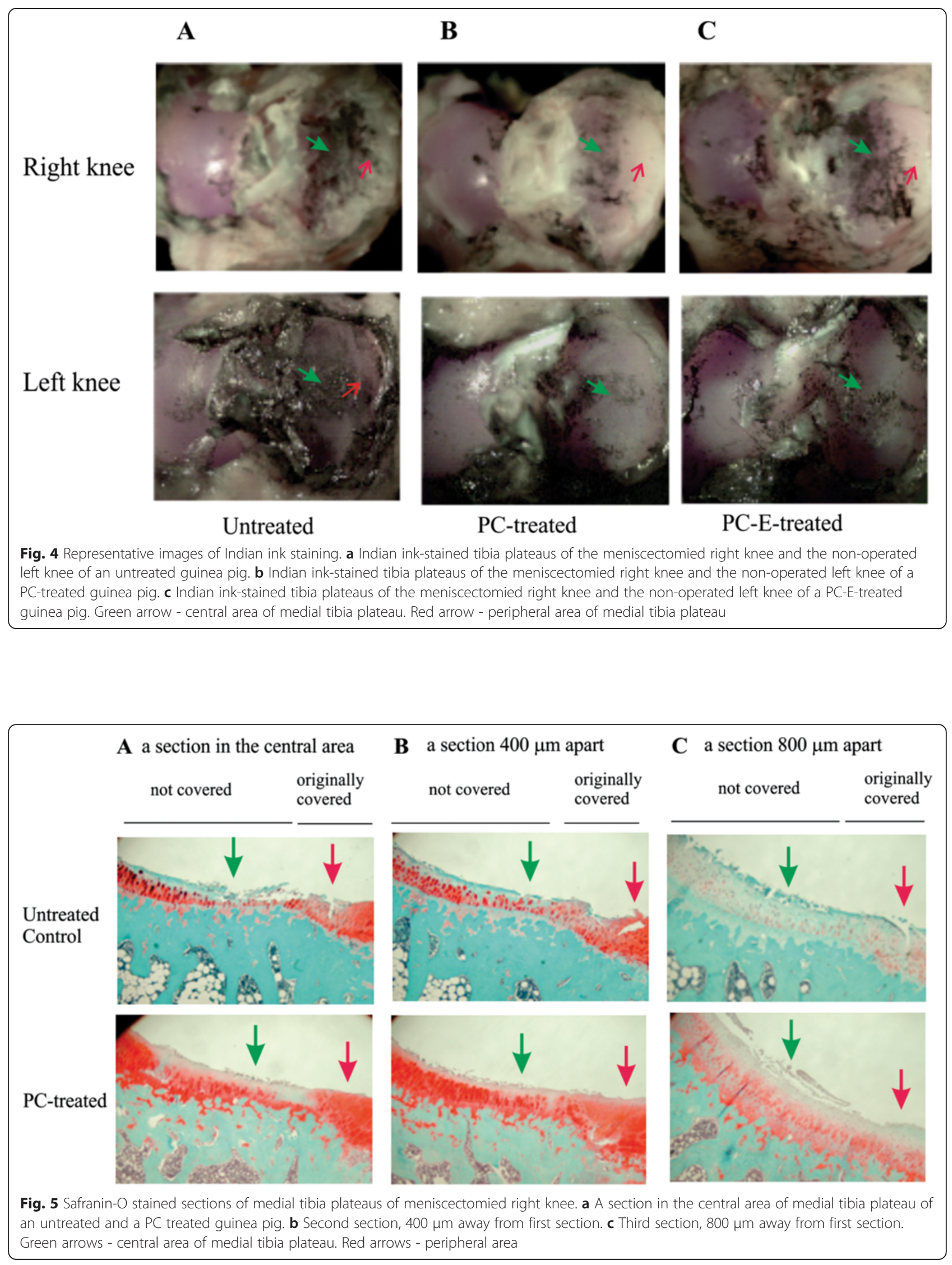
untreated guinea pigs. Cartilage damage and proteoglycan loss, in many cases, extended into deep and calcified zones. Cartilage damage and proteoglycan loss were significantly reduced in PC treated guinea pigs. In the central area of medial tibia plateaus, mild to moderate cartilage damage and proteoglycan loss were observed, whereas in the peripheral area, only mild cartilage damage and proteoglycan loss were observed. Consistent with Indian ink staining, cartilage damage and proteoglycan loss were also reduced in PC-E treated guinea pigs (photos not shown).

In addition, cartilage in untreated guinea pigs appeared thinner than the cartilage in PC treated guinea pigs (Fig. 5). We measured the cartilage thickness of all guinea pigs as described. As shown in Fig. 6a, cartilage in PC treated guinea pigs was $31 \%$ thicker than the cartilage in untreated guinea pigs $(p=0.01)$. Similarly, PC-E also inhibited cartilage thinning. Cartilage in PC-E treated guinea pigs was $18 \%$ thicker than the cartilage in untreated guinea pigs $(p=0.02)$.

These safranin-O stained sections (nine sections for each tibia plateau specimen) were graded. As shown in Fig. 6b, PC and PC-E significantly reduced the histologic score of medial tibia plateau (black bars), resulting in a 46 and $30 \%$ reduction in the histological scores, respectively $(p<0.05)$. For comparison, safranin-O stained sections in the non-operated left knee medial tibia plateau were graded. The histological score of the medial tibia plateau in the non-operated left knee was much lower than the histological score of the medial tibia plateau in the meniscectomied right knee $(p<0.01)$, confirming that meniscal injury and joint instability resulted in significantly increased cartilage damage. PC and PC-E reduced the histologic score of the medial tibia plateau in the non-operated left knee (grey bars), resulting in a 54 and $28 \%$ reduction in the histological scores, respectively $(p<0.05)$.

Due to severe cartilage damage being observed in the peripheral area of the medial tibia plateau in the meniscectomied right knee but not in the non-operated left knee, we decided to grade the peripheral area specifically. As shown in Fig. 6c, meniscal injury and joint instability in the meniscectomied right knee resulted in severe cartilage degeneration in the peripheral area compared to the non-operated left knee. Cartilage damage in the peripheral area of the medial tibia plateau in the meniscectomied right knee was significantly reduced in PC and PC-E treated guinea pigs, indicating again that PC and its analogue inhibits injury and joint instabilityinduced cartilage degeneration.

Two sections in each tibia plateau were also stained with picrosirius red and counter-stained with alcian blue. Representative images of picrosirius red stained sections are provided in Fig. 7. As shown, severe cartilage damage was observed in the untreated guinea pigs and in many cases,
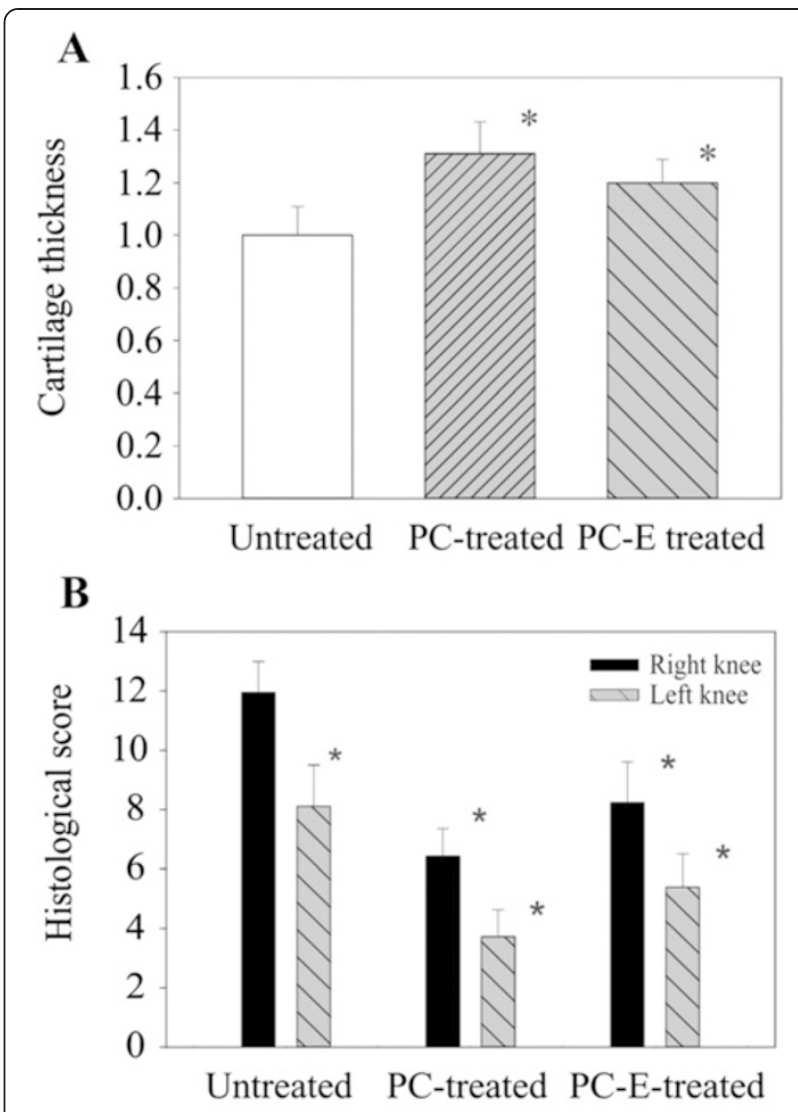

C

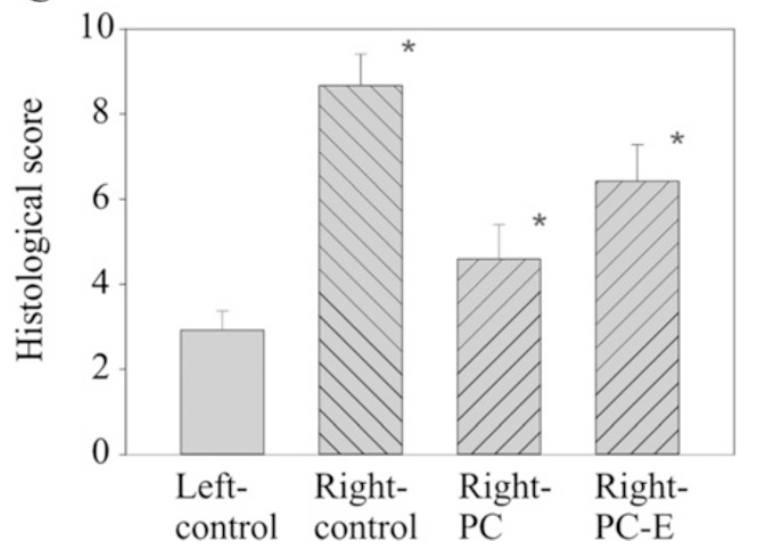

Fig. 6 Cartilage thickness and histological scores of medial tibia plateaus. a Normalized cartilage thickness in untreated, PC-treated, and PC-E treated guinea pigs are $1( \pm 0.11), 1.31( \pm 0.13)$, and $1.18( \pm 0.10)$. * $p<0.01$, versus controls. $\mathbf{b}$ Histological scores of medial tibia plateau in the meniscectomied right knee in untreated, PC, and PC-E treated guinea pigs are $11.95( \pm 1.05), 6.43( \pm 0.93)$, and 8.24 ( $\pm 0.1 .37)$. Histological scores of medial tibia plateau in the non-operated left knee in untreated, $P C$, and PC-E treated guinea pigs are 8.11 ( \pm 1.39$), 3.72( \pm 0.91)$, and 5.74 $( \pm 0.12) .{ }^{*} p<0.05$, versus controls. $\mathbf{c}$ Histological scores of the peripheral area of medial tibia plateau in the non-operated left knee and the meniscectomied right knee of untreated guinea pigs are $2.92( \pm 0.45)$ and 8.67 ( \pm 0.74$)$. Histological scores of the peripheral area of medial tibia plateau in the meniscectomied right knee of PC and PC-E treated guinea pigs are $4.59( \pm 0.81)$ and $6.42( \pm 0.0 .86) .{ }^{*} p<0.05$, versus controls 


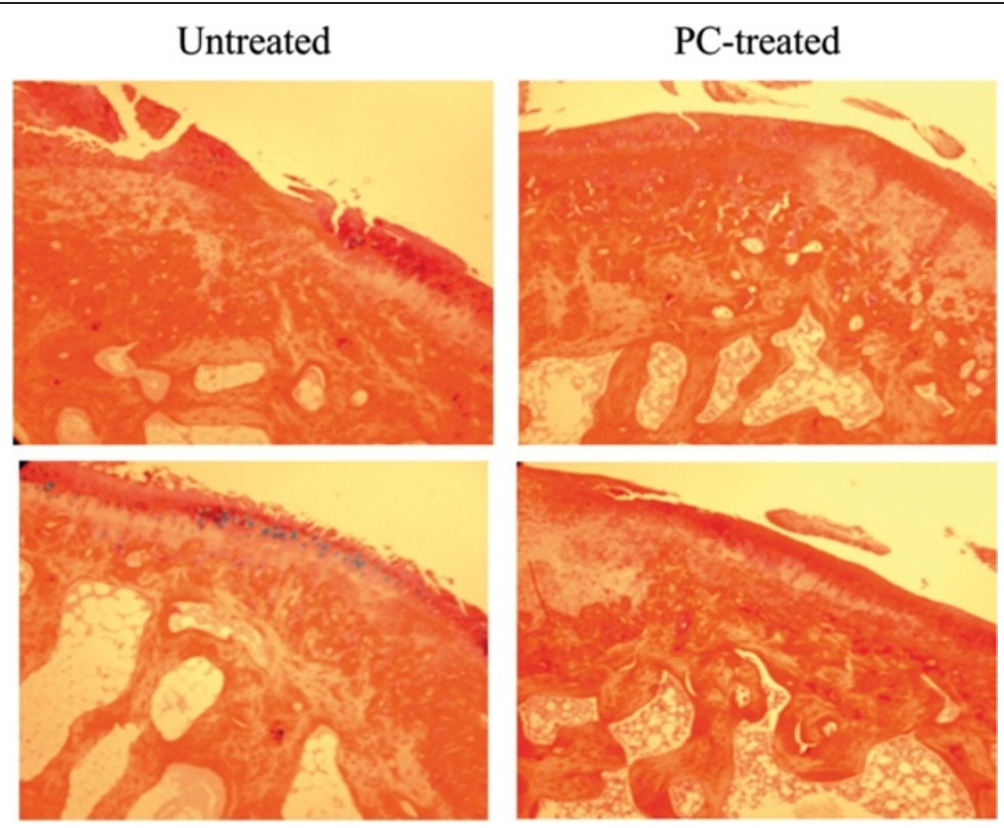

Fig. 7 Picrosirius red stained sections. Left: section at the central area of the medial tibia plateau from two untreated guinea pigs. Right: section at the central area of the medial tibia plateau from two PC treated guinea pigs

cartilage lesions extended into the middle, deep, and calcified zones. In contrast, cartilage damage was much less prominent in PC treated guinea pigs. Surprisingly, unlike the severe loss of safranin-O staining, there was no severe loss of picrosirius red staining in untreated guinea pigs compared to PC treated guinea pigs. These findings indicate that OA cartilage in the untreated Hartley guinea pigs was characterized by breakdown of collagen fibers, not by collagen loss. Interestingly, alcian blue staining was observed in some chondrocytes residing in the middle zone of articular cartilage in the untreated guinea pig, which was not observed in the cartilage of PC-treated guinea pigs. One explanation for this finding is that some chondrocytes in OA cartilage synthesize more proteoglycans in response to matrix degeneration. Consistent with this explanation, the intensity of safranin-O staining in the nucleus and cytoplasm of some chondrocytes in the untreated guinea pigs appeared much higher than the intensity of safranin-O staining in the nucleus and cytoplasm of most chondrocytes in the PC-treated guinea pigs (Fig. 5). Severe loss of safranin-O staining in the articular cartilage of untreated guinea pigs mainly occurred in the extracellular matrix space (Fig. 5).

\section{Immunohistochemistry}

Representative images of immunostaining are provided in Fig. 8a. In untreated guinea pigs, high levels of ADAMTS-5 protein was present in superficial, middle, and deep zones, whereas high level of MMP-13 protein was present in the middle and deep zones. The level of ADAMTS5 protein was reduced in PC and PC-E treated guinea pigs. The level of MMP-13 protein was also reduced, especially in the middle zone in PC treated guinea pigs. However, the level of MMP-13 protein appeared only slightly reduced in PC-E treated guinea pigs. In untreated guinea pigs, CCL-5 protein was present in superficial, middle, and deep zones, whereas Cox- 2 protein was present in superficial and middle zones. It was clear that the level of CCL-5 protein was reduced in PC and PC-E treated guinea pigs. However, the level of Cox-2 protein appeared only slightly reduced in PC and $\mathrm{PC}-\mathrm{E}$ treated guinea pigs compared to the untreated controls.

The scores of these immunostainings are provided in Fig. 9. As shown, PC and PC-E treatments resulted in $42 \%$ and $38 \%$ reductions in the immunostaining score of ADAMTS5, respectively $(p<0.05)$. PC treatment also resulted in $44 \%$ reduction in the immunostaining score of MMP-13 $(p<0.05)$. Although PC-E treatment resulted in reduction in the immunostaining score of MMP-13 (16\%), the difference did not reach statistical significance. PC and PC-E treatment resulted in $35 \%$ and $40 \%$ reductions in the immunostaining score of CCL-5, respectively $(p<0.05)$. Although $\mathrm{PC}$ and $\mathrm{PC}-\mathrm{E}$ treatments resulted in reductions in the immunostaining score of Cox-2 (about 10-14\% reductions), the differences did not reach statistical significance.

\section{The effect of PC-E on gene expressions}

We have shown that PC downregulated the expression of numerous genes classified in cell proliferation, angiogenesis, 


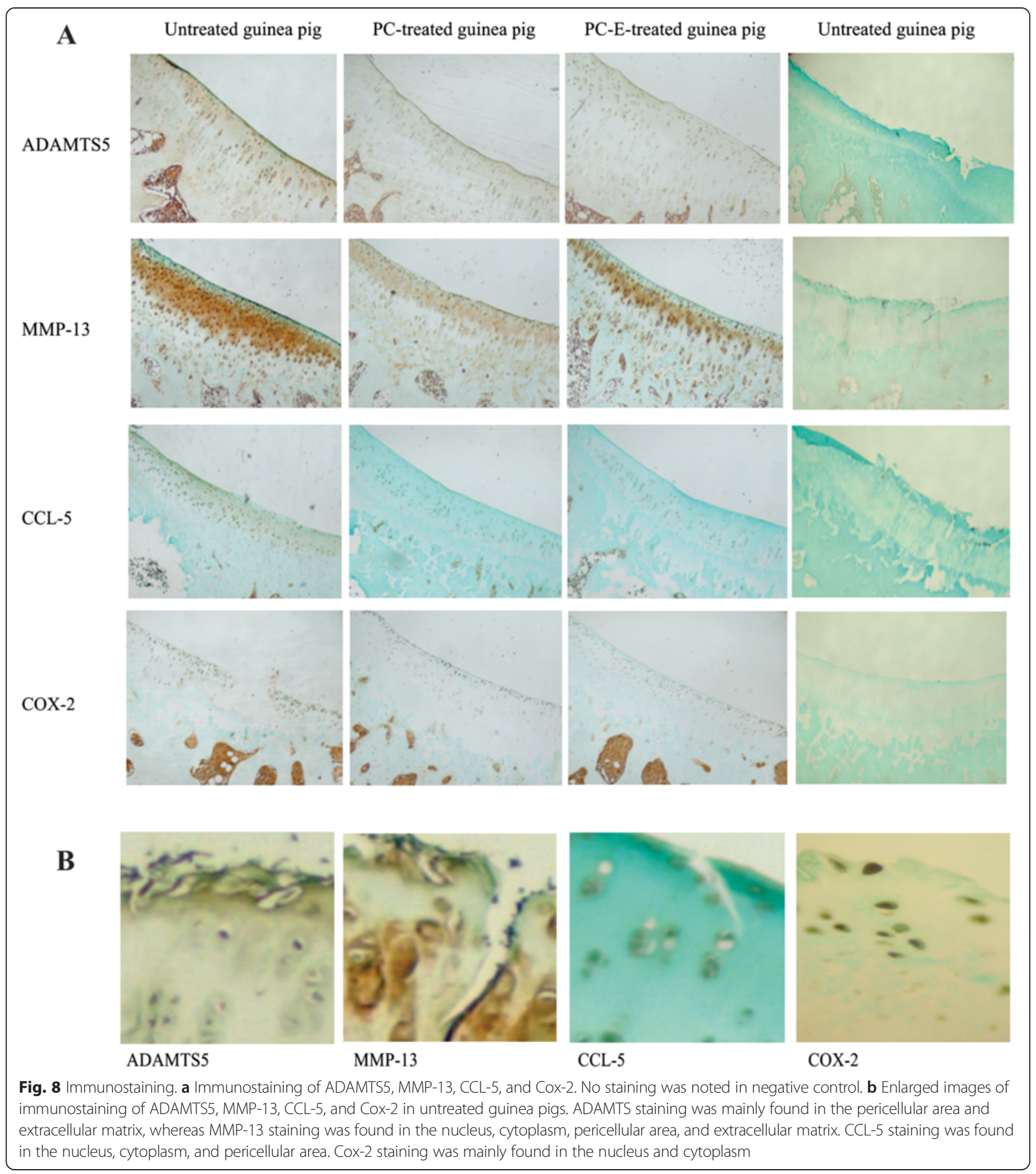

and inflammatory response while upregulating the expression of many genes classified in skeletal system development in the absence of calcium crystals [29]. To examine the molecular mechanisms underlying the decreased disease-modifying activity of PC-E, we compared the effect of PC-E on gene expressions with the effect of $\mathrm{PC}$ on gene expressions [29]. As shown in Table 1, PC-E downregulated almost all of the PC-downregulated genes classified in cell proliferation, suggesting that PC-E may inhibit cell proliferation as effectively as PC. However, PC-E had little effect on the expression of most of the PC downregulated genes classified in angiogenesis and inflammatory response, including prostaglandin-endoperoxide synthase 2 (PTGS2/Cox-2). PC-E also had little effect on the 


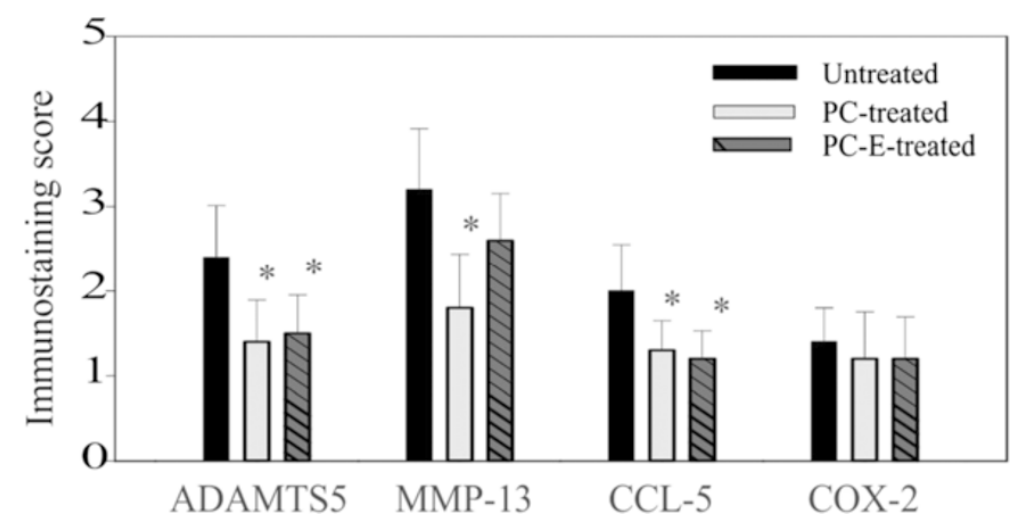

Fig. 9 Scores of immunostaining. Scores for ADAMTS5 immunostaining in untreated, PC, and PC-E treated guinea pigs are 2.40 $( \pm 0.61), 1.40( \pm 0.49)$, and $1.50( \pm 0.45)$; Scores for MMP-13 immunostaining are $3.20( \pm 0.71), 1.80( \pm 0.64)$, and $2.70( \pm 0.55)$; Scores for CCL-5 immunostaining are $2.00( \pm 0.55)$, $1.30( \pm 0.35)$, and $1.20( \pm 0.33)$; Scores for Cox-2 immunostaining are $1.40( \pm 0.40), 1.20( \pm 0.55)$, and $1.20( \pm 0.49)$. * $p<0.05$, versus controls

expressions of most of the PC upregulated genes classified in muscle tissue and skeletal system development (Table 2).

\section{Discussion}

PC, PC-E, and EHDP are powerful calcification inhibitors, suggesting that the phosphate group within these molecules play a key role in their calcification-inhibitory activity. These findings cast some doubt about the role of the calcification-inhibitory activity of these molecules in their OA disease-modifying activity because bisphosphonates displayed little disease-modifying effect on the animal model of OA [27, 28]. PC, consistent with previous findings $[18,26]$, is more powerful than EHDP as a calcification inhibitor, suggesting that the three carboxyl groups also play a key role in the calcification-inhibitory activity of PC. However, replacement of the $\beta$-carboxyl group with a $\beta$-ester group only resulted in a moderate $19 \%$ reduction in the calcification-inhibitory activity of $\mathrm{PC}$, indicating that three carboxyl groups are required for the strong calcification-inhibitory activity and that a single carboxyl group only plays a moderate role in the calcification-inhibitory activity of PC.

PC-E, similar to PC, inhibited the proliferation of OA FLSs. Consistent with this finding, PC-E downregulated the expressions of almost all of the PC-downregulated genes classified in cell proliferation as effectively as PC (Table 1). These findings indicate that the $\beta$-carboxyl group plays little role in the proliferation-inhibitory activity of $\mathrm{PC}$ and that the phosphate group within these molecules plays a key role in the proliferation-inhibitory activity [29]. Because PC-E is much less powerful than $\mathrm{PC}$ as an OA disease-modifying drug, it suggests that the proliferation-inhibitory activity of PC plays little role in its OA disease-modifying activity and that those PC downregulated genes classified in cell proliferation are unlikely key OA disease candidate genes.
Medial meniscal calcification is absent in the meniscectomied right knee and severe articular cartilage calcification is not observed in the Hartley guinea pigs [24]; therefore, $\mathrm{OA}$ in the meniscectomied right knee was mainly induced by meniscal injury and joint instability, and had less to do with pathological calcification. In this model of posttraumatic OA, PC significantly reduced cartilage damage and proteoglycan loss, demonstrating that $\mathrm{PC}$ is a disease-modifying drug for posttraumatic OA therapy. We should point out that our finding and conclusion contradict with a previous study. Cheung et al. found that PC had no significant effect on cartilage degeneration in partial meniscectomied rabbits, and concluded that PC is potentially a disease-modifying drug for calcification-induced OA, but not for noncalcification-induced OA [24]. One possible explanation for these contradicting findings is that different doses of PC were used in the two studies. A single weekly injection $(40 \mathrm{mg} / \mathrm{kg})$ was used in the previous study whereas two weekly injections of PC $(40 \mathrm{mg} / \mathrm{kg})$ were used in this study. It is worth noting that PC treatment did reduce the histological score of the medial tibia in the rabbit (from $9.8 \pm 1.7$ to $8.1 \pm 2.2$ ) [24]. If higher doses or more injections of PC per week was used, statistically significant difference might have been observed.

The molecular mechanisms underlying the diseasemodifying effect of PC remain poorly understood. If PC exerted its disease-modifying effect solely by inhibiting the formation of articular crystals, PC should have displayed little disease-modifying effect on posttraumatic OA. Moreover, PC-E should have displayed only moderately decreased disease-modifying effect on posttraumatic OA compared to PC because PC-E is still a powerful calcification inhibitor. However, we found that PC significantly inhibited cartilage degeneration and that PC-E was $46 \%$ less powerful than PC in the inhibition of cartilage degeneration in the meniscectomied right 
Table 1 Differentially expressed genes in PC-treated and PC-E-treated cells compared with untreated cells

\begin{tabular}{|c|c|c|c|c|c|}
\hline Biological process & Gene name & Gene ID & $\begin{array}{l}\text { Differ Expre (fold)* } \\
\text { PC }\end{array}$ & $\begin{array}{l}\text { Differ Expre }(\text { fold })^{* *} \\
\text { PC-E }\end{array}$ & Description \\
\hline \multicolumn{6}{|l|}{ Cell proliferation } \\
\hline & BLM & NM_000057 & -3.64 & -1.78 & Bloom syndrome \\
\hline & CCNE2 & AF112857 & -3.74 & 0.00 & Cyclin E2 \\
\hline & CCNE1 & Al671049 & -2.30 & 0.00 & Cyclin E1 \\
\hline & $\mathrm{CDC} 25 \mathrm{~A}$ & AY137580 & -3.63 & 0.00 & Cell division cycle 25 homolog A (S. pombe) \\
\hline & CDC25C & NM_001790 & -2.31 & 0.00 & Cell division cycle 25 homolog C (S. pombe) \\
\hline & $\mathrm{CDC2}$ & AA749427 & -3.13 & -3.42 & Cell division cycle 2, G1 to $S$ and $G 2$ to $M$ \\
\hline & CDC6 & NM_001254 & -2.36 & -9.19 & Cell division cycle 6 homolog (S. cerevisiae) \\
\hline & CDC7 & NM_003503 & -2.12 & -4.42 & Cell division cycle 7 homolog (S. cerevisiae) \\
\hline & CDCA3 & NM_031299 & -1.83 & -2.61 & Cell division cycle associated 3 \\
\hline & CDCA5 & BE614410 & -2.41 & -3.37 & Cell division cycle associated 5 \\
\hline & CDCA7 & AY029179 & -2.36 & -4.60 & Cell division cycle associated 7 \\
\hline & CDCA8 & BC001651 & -2.11 & -2.12 & Cell division cycle associated 8 \\
\hline & CDK2 & AB012305 & -2.74 & -3.36 & Cyclin-dependent kinase 2 \\
\hline & $\mathrm{NCAPH}$ & D38553 & -2.64 & -2.21 & Non-SMC condensin I complex, subunit H \\
\hline & HELLS & NM_018063 & -2.49 & -4.77 & Helicase, lymphoid-specific \\
\hline & AURKB & AB011446 & -2.43 & 0.00 & Aurora kinase B \\
\hline & KIF23 & AW192521 & -2.41 & -3.83 & Kinesin family member 23 \\
\hline & CLASP2 & BC029035 & -2.40 & 0.00 & Cytoplasmic linker associated protein 2 \\
\hline & NUF2 & AF326731 & -2.35 & -4.04 & $\begin{array}{l}\text { NUF2, NDC80 kinetochore complex component, } \\
\text { homolog }\end{array}$ \\
\hline & DSN1 & NM_024918 & -2.35 & -3.09 & $\begin{array}{l}\text { DSN1, MIND kinetochore complex component, } \\
\text { homolog }\end{array}$ \\
\hline & SPC24 & Al469788 & -2.32 & 0.00 & $\begin{array}{l}\text { SPC24, NDC80 kinetochore complex component, } \\
\text { homolog }\end{array}$ \\
\hline & SPC25 & AF225416 & -2.10 & -3.40 & $\begin{array}{l}\text { SPC25, NDC80 kinetochore complex component, } \\
\text { homolog }\end{array}$ \\
\hline & HMGA2 & Al990940 & -2.30 & -3.41 & High mobility group AT-hook 2 \\
\hline & LIG1 & NM_000234 & -2.25 & -2.20 & Ligase I, DNA, ATP-dependent \\
\hline & $\mathrm{KIFC1}$ & BC000712 & -2.21 & -2.08 & Kinesin family member $\mathrm{C} 1$ \\
\hline & BRCA2 & X95152 & -2.18 & 0.00 & Breast cancer 2, early onset \\
\hline & ERCC6L & NM_017669 & -2.17 & -2.29 & $\begin{array}{l}\text { Exc repair cross-comp repair deficiency, comp group } \\
6 \text {-like }\end{array}$ \\
\hline & SPAG5 & NM_006461 & -2.16 & -2.61 & Sperm associated antigen 5 \\
\hline & NEK2 & Z25425 & -2.14 & -2.20 & NIMA (never in mitosis gene a)-related kinase 2 \\
\hline & NCAPG & NM_022346 & -2.12 & -4.06 & Non-SMC condensin I complex, subunit G \\
\hline & ZWINT & NM_007057 & -2.01 & -3.93 & ZW10 interactor antisense \\
\hline & PARD3B & AF428251 & 3.24 & 1.68 & Par-3 partitioning defective 3 homolog B (C. elegans) \\
\hline & 11-Sep & Al333326 & 2.28 & 0.00 & Septin 11 \\
\hline \multicolumn{6}{|l|}{ Angiogenesis } \\
\hline & NRP1 & AF280547 & -2.69 & 0.00 & Neuropilin 1 \\
\hline & TEK & BF594294 & -2.58 & -1.73 & TEK tyrosine kinase, endothelial \\
\hline & ELK3 & NM_005230 & -2.42 & 0.00 & ELK3, ETS-domain protein (SRF accessory protein 2) \\
\hline & EREG & NM_001432 & -1.90 & 0.00 & Epiregulin \\
\hline & PML & AW291023 & -1.89 & 0.00 & Promyelocytic leukemia \\
\hline
\end{tabular}


Table 1 Differentially expressed genes in PC-treated and PC-E-treated cells compared with untreated cells (Continued)

\begin{tabular}{|c|c|c|c|c|c|}
\hline & COL15A1 & NM_001855 & -1.80 & 0.00 & Collagen, type XV, alpha 1 \\
\hline & NRP2 & Al819729 & -1.75 & 0.00 & Neuropilin 2 \\
\hline & SPHK1 & NM_021972 & -1.72 & 0.00 & Sphingosine kinase 1 \\
\hline & FOXC2 & NM_005251 & -1.68 & 0.00 & Forkhead box C2 (MFH-1, mesenchyme forkhead 1) \\
\hline & SCG2 & NM_003469 & -1.66 & 2.54 & Secretogranin II (chromogranin C) \\
\hline & EDNRA & NM_001957 & -1.56 & 0.00 & Endothelin receptor type A \\
\hline & TGFBR2 & NM_003242 & -1.51 & -1.97 & $\begin{array}{l}\text { Transforming growth factor, beta receptor II (70/ } \\
80 \mathrm{kDa} \text { ) }\end{array}$ \\
\hline & $\mathrm{ROBO} 4$ & AA156022 & -1.51 & 0.00 & $\begin{array}{l}\text { Roundabout homolog 4, magic roundabout } \\
\text { (Drosophila) }\end{array}$ \\
\hline & JAG1 & Al457817 & 2.42 & 1.76 & Jagged 1 (Alagille syndrome) \\
\hline & $\mathrm{NOTCH} 4$ & Al341271 & 1.75 & 0.00 & Notch homolog 4 (Drosophila) \\
\hline & RUNX1 & D89788 & 1.73 & 0.00 & Runt-related transcription factor 1 \\
\hline & EPAS1 & NM_001430 & 1.67 & 0.00 & Endothelial PAS domain protein 1 \\
\hline \multicolumn{6}{|l|}{$\begin{array}{l}\text { Inflammatory } \\
\text { response }\end{array}$} \\
\hline & PTGS2 & AY151286 & -6.09 & 0.00 & Prostaglandin-endoperoxide synthase 2 \\
\hline & SERPINA1 & AF119873 & -2.15 & 0.00 & Serpin peptidase inhibitor, clade A \\
\hline & GPR68 & Al805006 & -2.15 & -2.44 & G protein-coupled receptor 68 \\
\hline & BMPR1B & AA935461 & -2.12 & 0.00 & Bone morphogenetic protein receptor, type IB \\
\hline & EVI1 & BE466525 & -2.00 & -1.69 & Ecotropic viral integration site 1 \\
\hline & FOS & BC004490 & -1.92 & 1.51 & $\begin{array}{l}\text { V-fos FBJ murine osteosarcoma viral oncogene } \\
\text { homolog }\end{array}$ \\
\hline & IRAK2 & Al246590 & -1.82 & 0.00 & Interleukin-1 receptor-associated kinase 2 \\
\hline & CCL2 & S69738 & -1.82 & 0.00 & Chemokine (C-C motif) ligand 2 \\
\hline & CCR1 & NM_001295 & -1.60 & 0.00 & Chemokine (C-C motif) receptor 1 \\
\hline & CXCL2 & M57731 & -1.66 & 0.00 & Chemokine (C-X-C motif) ligand 2 \\
\hline & SPN & BC035510 & -1.79 & 0.00 & Sialophorin (leukosialin, CD43) \\
\hline & TLR4 & AF177765 & -1.70 & 0.00 & toll-like receptor 4 \\
\hline & SCG2 & NM_003469 & -1.66 & 2.54 & Secretogranin II (chromogranin C) \\
\hline & FN1 & AJ276395 & -1.58 & -1.52 & Fibronectin 1 \\
\hline & KLKB1 & BE326857 & -1.52 & 0.00 & $\begin{array}{l}\text { Cytochrome P450, family 4, subfamily V, polypeptide } \\
2\end{array}$ \\
\hline & NDST1 & NM_001543 & 2.05 & 0.00 & $\begin{array}{l}\text { N-deacetylase/N-sulfotransferase (heparan } \\
\text { glucosaminyl) } 1\end{array}$ \\
\hline & $\mathrm{C} 3$ & NM_000064 & 2.05 & 0.00 & Complement component 3 \\
\hline & SERPINA3 & NM_001085 & 1.88 & 0.00 & Serpin peptidase inhibitor, clade A \\
\hline & $\mathrm{SBNO} 2$ & AC005390 & 1.78 & 0.00 & strawberry notch homolog 2 (Drosophila) \\
\hline & NFKBIZ & BE646573 & 1.74 & 0.00 & NF-KB inhibitor zeta \\
\hline & MASP1 & NM_001879 & 1.64 & 0.00 & Mannan-binding lectin serine peptidase 1 \\
\hline & STAT5B & NM_012448 & 1.59 & 0.00 & Signal transducer and activator of transcription 5B \\
\hline
\end{tabular}

* Negative number indicates decreased expression (fold) in treated hTERT-OA 13A FLS compared with untreated cells Positive number indicates elevated expression (fold) in treated hTERT-OA 13A FLS compared with the untreated cells **Dada was published previously [29]

knee. These findings indicate that crystal-dependent action is unlikely the sole action underlying the diseasemodifying effect of PC or PC-E. PC and PC-E likely exert their disease-modifying activity through both a crystal-dependent action and a crystal-independent action. Consistent with this mechanism, PC-E had no effect on the expressions of PC downregulated genes classified in angiogenesis and inflammatory response 
Table 2 Differentially expressed genes in PC-treated and PC-E-treated cells compared with untreated cells

\begin{tabular}{|c|c|c|c|c|c|}
\hline Biological process & Gene name & Gene ID & $\begin{array}{l}\text { Differ Expre (fold)* } \\
\text { PC }\end{array}$ & $\begin{array}{l}\text { Differ Expre }(\text { fold })^{* *} \\
\text { PC-E }\end{array}$ & Description \\
\hline \multicolumn{6}{|l|}{$\begin{array}{l}\text { Muscle tissue } \\
\text { development }\end{array}$} \\
\hline & IGFBP5 & AW157548 & 8.57 & 1.55 & Insulin-like growth factor binding protein 5 \\
\hline & CACNB4 & NM_000726 & 2.73 & 0.00 & Calcium channel, voltage-dependent, beta 4 subunit \\
\hline & TPM1 & Al521618 & 2.43 & 0.00 & Tropomyosin 1 (alpha) \\
\hline & JAG1 & U61276 & 2.02 & 0.00 & Jagged 1 (Alagille syndrome) \\
\hline & MORF4L2 & H43976 & 1.90 & 0.00 & Mortality factor 4 like 2 \\
\hline & NRG1 & NM_013957 & 1.88 & 0.00 & Neuregulin 1 \\
\hline & SIRT2 & BG722779 & 1.86 & 0.00 & $\begin{array}{l}\text { Sirtuin (silent mating type information regulation } 2 \\
\text { homolog) } 2\end{array}$ \\
\hline & NF1 & D12625 & 1.80 & 0.00 & Neurofibromin 1 \\
\hline & OBSL1 & BF446688 & 1.78 & 0.00 & Obscurin-like 1 \\
\hline & MBNL1 & AA732240 & 1.73 & 0.00 & Muscleblind-like (Drosophila) \\
\hline & TPM1 & NM_000366 & 1.72 & 0.00 & Tropomyosin 1 (alpha) \\
\hline & CAV2 & AA150110 & 1.67 & 0.00 & Caveolin 2 \\
\hline & RXRA & BE675800 & 1.66 & 0.00 & Retinoid $\mathrm{X}$ receptor, alpha \\
\hline & $\mathrm{NR} 2 \mathrm{~F} 2$ & AL554245 & 1.63 & 0.00 & Nuclear receptor subfamily 2, group F, member 2 \\
\hline & TCF7L2 & AV721430 & 1.61 & 2.00 & Transcription factor 7-like 2 (T-cell specific, HMG-box) \\
\hline & TBX2 & U28049 & -4.17 & 0.00 & T-box 2 \\
\hline & ADRB2 & NM_000024 & -2.36 & 0.00 & Adrenergic, beta-2-, receptor, surface \\
\hline & SORT1 & BE742268 & -1.93 & 0.00 & Sortilin 1 \\
\hline & GJC1 & NM_005497 & -1.77 & -3.09 & Gap junction protein, gamma 1, 45 kDa \\
\hline & CENPF & U30872 & -1.77 & 0.00 & Centromere protein F, 350/400 ka (mitosin) \\
\hline & $\mathrm{BCL} 2$ & NM_000657 & -1.71 & 1.55 & B-cell CLL/lymphoma 2 \\
\hline & TBX3 & U69556 & -1.71 & 1.77 & T-box 3 \\
\hline & SDC1 & NM_002997 & -1.65 & -1.89 & Syndecan 1 \\
\hline & TBX5 & AW269421 & -1.54 & 0.00 & T-box 5 \\
\hline & RARB & NM_015854 & -1.51 & 0.00 & Retinoic acid receptor, beta \\
\hline \multicolumn{6}{|c|}{ Skeletal development } \\
\hline & ANXA2 & D28364 & 2.17 & 0.00 & Annexin A2 \\
\hline & VDR & AA772285 & 2.11 & 0.00 & Vitamin D (1,25- dihydroxyvitamin D3) receptor \\
\hline & GNAS & Al693143 & 1.95 & 1.60 & GNAS complex locus \\
\hline & ACAN & NM_001135 & 1.80 & -1.51 & Aggrecan \\
\hline & COL1A1 & Al743621 & 1.66 & 0.00 & Collagen, type I, alpha 1 \\
\hline & COL1A2 & AA628535 & 1.88 & 0.00 & Collagen, type I, alpha 2 \\
\hline & COL11A1 & NM_001854 & 1.50 & 0.00 & Collagen, type XI, alpha 1 \\
\hline & COL12A1 & AU146651 & 1.93 & 1.51 & Collagen, type XII, alpha 1 \\
\hline & MSX2 & D89377 & 1.85 & 0.00 & Msh homeobox 2 \\
\hline & GHR & NM_000163 & 1.76 & 0.00 & Growth hormone receptor \\
\hline & MEF2C & AL536517 & 1.59 & 0.00 & Myocyte enhancer factor $2 \mathrm{C}$ \\
\hline & THRA & NM_003250 & 1.57 & 1.60 & Thyroid hormone receptor, alpha \\
\hline & RUNX2 & AW469546 & 1.55 & 1.89 & Runt-related transcription factor 2 \\
\hline & CLEC3B & NM_003278 & 1.55 & 3.26 & Exosome component 7 \\
\hline & MEF2C & N22468 & 1.55 & 0.00 & Myocyte enhancer factor $2 \mathrm{C}$ \\
\hline
\end{tabular}


Table 2 Differentially expressed genes in PC-treated and PC-E-treated cells compared with untreated cells (Continued)

\begin{tabular}{llllll}
\hline IGFBP4 & NM_001552 & 1.54 & 0.00 & 0.00 & Insulin-like growth factor binding protein 4 \\
PRKRA & AA279462 & 1.53 & & $\begin{array}{l}\text { Protein kinase, interferon-inducible RNA dependent } \\
\text { activator }\end{array}$ \\
TNFRSF11B & NM_002546 & 1.50 & -2.76 & $\begin{array}{l}\text { Tumor necrosis factor receptor superfamily, member } \\
\text { 11b }\end{array}$ \\
BMPR1B & AA935461 & -2.12 & 0.00 & Bone morphogenetic protein receptor, type IB \\
ANKH & AF274753 & -1.93 & -1.71 & Ankylosis, progressive homolog (mouse) \\
ACVR2A & NM_001616 & -1.89 & 0.00 & Activin A receptor, type IIA \\
CYTL1 & NM_018659 & -1.83 & 0.00 & Cytokine-like 1 \\
TBX3 & U69556 & -1.71 & 1.77 & T-box 3 (ulnar mammary syndrome) \\
SOX9 & NM_000346 & -1.71 & 0.00 & SRY (sex determining region Y)-box 9 \\
FOXC2 & NM_005251 & -1.68 & 0.00 & Forkhead box C2 (MFH-1, mesenchyme forkhead 1) \\
KIAA1217 & BC017424 & -1.66 & 0.00 & KIAA1217 \\
MMP9 & NM_004994 & -1.61 & 0.00 & Matrix metallopeptidase 9 \\
TGFBR2 & NM_003242 & -1.51 & -1.97 & Transforming growth factor, beta receptor II \\
\end{tabular}

*Negative number indicates decreased expression (fold) in treated hTERT-OA 13A FLS compared with untreated cells Positive number indicates elevated expression (fold) in treated hTERT-OA 13A FLS compared with the untreated cells

**Data was published previously [29]

and PC upregulated genes classified in skeletal system development; therefore, resulting in decreased OA diseasemodifying activity. Taken together, it suggests that the gene expression-modulatory activity of PC may play an important role in its OA disease-modifying activity.

We demonstrated that $\mathrm{PC}$ reduced the levels of ADAMTS5 and MMP-13 proteins. It is worth noting that the level of MMP-13 protein is much higher in the middle zone than in the superficial and calcified zones (Fig. 7). In human OA articular cartilage, calcium crystals are detected in the superficial and calcified zones [39-41]. If calcium crystals are also present in the superficial or calcified zones of articular cartilage in the guinea pigs and those crystals played a key role in the induction of MMP-13 expression [42], high level of MMP13 protein should have been observed in the superficial zone or calcified zone. Similarly, if the reduction in the level of MMP-13 protein in PC treated guinea pigs was due to the inhibition of $\mathrm{PC}$ on the interaction between calcium crystals and chondrocytes [23], significant reduction in the level of MMP-13 protein should have been observed in the superficial zone or calcified zone, but not in the middle zone. However, these were not what we observed, indicating that calcium-containing crystals is unlikely a key inducer for the production of MMP-13 in the articular cartilage and that PC exerts its inhibitory effect on the production of MMP-13 through a crystal-independent action.

Our findings do suggest that crystal-dependent action of PC plays a role. For example, PC treatment resulted in a $46 \%$ reduction in the histological scores of cartilage in meniscectomied right knee but a $54 \%$ reduction in non-operated left knee. One explanation for this difference (46\% reduction via $54 \%$ reduction) is that pathological meniscal calcification plays a role in the nonoperated left knee $\mathrm{OA}[7,43]$. It is likely that PC exerts its disease-modifying effect on the posttraumatic OA in the right knee through a crystal-independent action whereas PC exerts its disease-modifying effect on the primary OA in the left knee through both a crystaldependent action and a crystal-independent action. It is conceivable that inhibition of cartilage degeneration through a single action (inhibiting non-crystal-dependent disease pathway) is less effective than through 2 actions (inhibiting both crystal-dependent disease pathway and non-crystal-dependent disease pathway).

PC-E was $46 \%$ less powerful than PC in the inhibition of cartilage degeneration in the non-operated left knee but was $33 \%$ less powerful than PC in the inhibition of cartilage degeneration in the meniscectomied right knee. Again, this difference (46\% reduction via $33 \%$ reduction) can be explained similarly. The replacement of $\beta$ carboxyl group with an ester group resulted in partial impairment of both crystal-dependent action and crystalindependent action of PC. It is conceivable that partial impairment of both actions would result in a greater loss in the disease-modifying effect on the primary OA in nonoperated left knee than on the posttraumatic OA in meniscectomied right knee because crystal-dependent disease pathway was absent in the right knee.

Our study has limitations. One limitation is that the OA in the meniscectomied right knee is not absolutely a noncalcification-induced OA because crystals must be present in the calcified zone. However, the increased severity of 
cartilage damage in the meniscectomied right knee compared to the non-operated left knee indicate that the most severe cartilage lesions in the right knee medial tibia plateau, especially the cartilage lesions in the peripheral area, were caused by meniscal injury and joint instability and has little to do with pathological calcification. In addition, a previous study found that PC had no significant effect on crystal formation in cartilage [16]. Taken together, it indicates that PC inhibits cartilage degeneration, at least in part, through a crystal-independent action.

\section{Conclusions}

Posttraumatic OA in Hartley guinea pigs are characterized by breakdown of collagen fibers and proteoglycan loss. PC is not only potentially a disease-modifying drug for calcification-induced OA therapy but also potentially a disease-modifying drug for posttraumatic OA therapy. PC exerts its disease-modifying activity on OA through two independent actions, a crystal-dependent action and a crystal-independent action. The $\beta$-carboxyl group plays little role in the proliferation-inhibitory activity and the modulatory effect on the expressions of genes classified in cell proliferation, but a major role in the OA disease-modifying activity and the modulatory effect on the expressions of genes classified in angiogenesis, inflammatory response, and skeletal system development of PC. The $\beta$-carboxyl group is not a group that should be used to link other active group(s) to create new PC analogues as OA disease-modifying drugs.

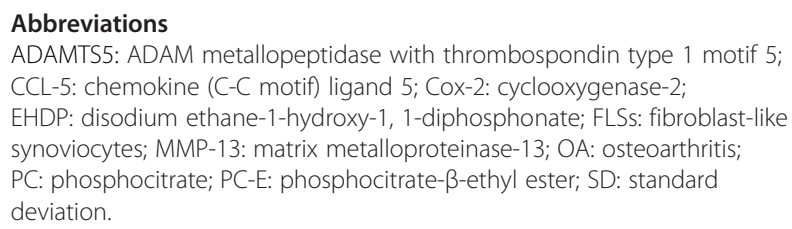

\section{Competing interests}

The authors declare that they have no competing interests.

\section{Authors' contributions}

YS, DRM and ENH conceived the study. YS wrote the manuscript. DRM and ENH participated in the discussion of experimental results and assisted with manuscript preparation. NH, MR and KLM performed the surgery and harvested tissues. AR, NH and YS took $x$-ray of the knee joints and menisci, and dissected the knee joints. AR and YS performed injection of PC, cartilage grading and data analysis. JI and MC performed embedding, sectioning and staining. All authors read and approved the final manuscript.

\section{Authors' information}

Not applicable.

\section{Acknowledgments}

This study is supported by a NC Biotech Center Grant to YS. This study was performed at Carolinas Medical Center, Charlotte, NC, USA.

\section{Author details}

'Department of Orthopedic Surgery, Carolinas Medical Center, PO Box 32861, Charlotte, NC 28232, USA. ${ }^{2}$ Department of Comparative Medicine, Carolinas Medical Center, PO Box 32861, Charlotte, NC 28232, USA.
Received: 6 August 2015 Accepted: 18 September 2015

Published online: 30 September 2015

\section{References}

1. Goldring SR, Goldring MB. The role of cytokines in cartilage matrix degeneration in osteoarthritis. Clin Orthop Relat Res. 2004;427:S27-36.

2. Martel-Pelletier J, Welsch DJ, Pelletier JP. Metalloproteases and inhibitors in arthritic diseases. Best Pract Res Clin Rheumatol. 2001;15:805-29.

3. Burrage PS, Brinckerhoff CE. Molecular targets in osteoarthritis: metalloproteinases and their inhibitors. Curr Drug Targets. 2007;8:293-303.

4. Derfus BA, Kurian JB, Butler JJ, Daft L, Carrera GF, Ryan LM, et al. The high prevalence of pathologic calcium crystals in pre-operative knees. J Rheumatol. 2002;29:570-4.

5. Nalbant S, Martinez JA, Kitumnuaypong T, Clayburne G, Sieck M, Schumacher Jr HR. Synovial fluid features and their relations to osteoarthritis severity: new findings from sequential studies. Osteoarthritis Cartilage. 2003;11:50-4.

6. Fuerst $M$, Bertrand J, Lammers $L$, Dreier R, Echtermeyer F, Nitschke $Y$, et al. Calcification of articular cartilage in human osteoarthritis. Arthritis Rheum. 2009;60:2694-703.

7. Sun Y, Mauerhan DR, Honeycutt PR, Kneisl JS, Norton HJ, Zinchenko N, et al. Calcium deposition in osteoarthritic meniscus and meniscal cell culture. Arthritis Res Ther. 2010;12:R56.

8. Abhishek A, Doherty M. Epidemiology of calcium pyrophosphate crystal arthritis and basic calcium phosphate crystal arthropathy. Rheum Dis Clin North Am. 2014;40:177-91.

9. Sun Y, Mauerhan DR, Franklin AM, Zinchenko N, Norton HJ, Hanley Jr EN, et al. Fibroblast-like synoviocytes induce calcium mineral formation and deposition. Arthritis. 2014;2014:812678.

10. McCarty DJ. Crystal-induced inflammation of the joints. Annu Rev Med. 1970;21:357-66.

11. Ea HK, Chobaz V, Nguyen C, Nasi S, van LP, Daudon M, et al. Pathogenic role of basic calcium phosphate crystals in destructive arthropathies. PLoS One. 2013;8:e57352.

12. McCarthy GM, Mitchell PG, Cheung HS. The mitogenic response to stimulation with basic calcium phosphate crystals is accompanied by induction and secretion of collagenase in human fibroblasts. Arthritis Rheum. 1991;34:1021-30.

13. Sun $Y$, Wenger $L$, Brinckerhoff $C E$, Misra RR, Cheung HS. Basic calcium phosphate crystals induce matrix metalloproteinase-1 through the Ras/ mitogen-activated protein kinase/c-Fos/AP-1/metalloproteinase 1 pathway. Involvement of transcription factor binding sites AP-1 and PEA-3. J Biol Chem. 2002;277:1544-52.

14. Ea HK, Uzan B, Rey C, Liote F. Octacalcium phosphate crystals directly stimulate expression of inducible nitric oxide synthase through p38 and JNK mitogen-activated protein kinases in articular chondrocytes. Arthritis Res Ther. 2005;7:R915-26.

15. Morgan MP, Whelan LC, Sallis JD, McCarthy CJ, Fitzgerald DJ, McCarthy GM. Basic calcium phosphate crystal-induced prostaglandin E2 production in human fibroblasts: role of cyclooxygenase 1, cyclooxygenase 2, and interleukin-1beta. Arthritis Rheum. 2004;50:1642-9.

16. Reddi AH, Meyer JL, Tew WP, Howard JE, Lehninger AL. Influence of phosphocitrate, a potent inhibitor of hydroxyapatite crystal growth, on mineralization of cartilage and bone. Biochem Biophys Res Commun. 1980;97:154-9.

17. Williams G, Sallis JD. Structure-activity relationship of inhibitors of hydroxyapatite formation. Biochem J. 1979;184:181-4.

18. Williams G, Sallis JD. Structural factors influencing the ability of compounds to inhibit hydroxyapatite formation. Calcif Tissue Int. 1982;34:169-77.

19. Shankar R, Crowden S, Sallis JD. Phosphocitrate and its analogue N-sulpho2-amino tricarballylate inhibit aortic calcification. Atherosclerosis. 1984;52:191-8.

20. Nair D, Misra RP, Sallis JD, Cheung HS. Phosphocitrate inhibits a basic calcium phosphate and calcium pyrophosphate dihydrate crystal-induced mitogen-activated protein kinase cascade signal transduction pathway. J Biol Chem. 1997;272:18920-5.

21. Cheung HS, Sallis JD, Struve JA. Specific inhibition of basic calcium phosphate and calcium pyrophosphate crystal-induction of metalloproteinase synthesis by phosphocitrate. Biochim Biophys Acta. 1996;1315:105-11. 
22. Sun $Y$, Reuben $P$, Wenger $L$, Sallis JD, Demadis KD, Cheung HS. Inhibition of calcium phosphate-DNA coprecipitates induced cell death by phosphocitrates. Front Biosci. 2005;10:803-8.

23. Cheung HS. Phosphocitrate as a potential therapeutic strategy for crystal deposition disease. Curr Rheumatol Rep. 2001;3:24-8.

24. Cheung HS, Sallis JD, Demadis KD, Wierzbicki A. Phosphocitrate blocks calcification-induced articular joint degeneration in a guinea pig model. Arthritis Rheum. 2006:54:2452-61.

25. Yutani Y, Ohashi H, Nishimura N, Yamano Y. Clinical effect of etidronate disodium (EHDP) on heterotopic ossification following total hip arthroplasty. Osaka City Med J. 1995;41:63-73.

26. Sun $Y$, Zeng XR, Wenger $L$, Cheung HS. Basic calcium phosphate crystals stimulate the endocytotic activity of cells-inhibition by anti-calcification agents. Biochem Biophys Res Commun. 2003;312:1053-9.

27. Ding M, Danielsen CC, Hvid I. The effects of bone remodeling inhibition by alendronate on three-dimensional microarchitecture of subchondral bone tissues in quinea pig primary osteoarthrosis. Calcif Tissue Int. 2008:82:77-86.

28. Walton M. The effects of long-term administration of ethane-1-hydroxy-1, 1-diphosphonate on osteoarthrosis and heterotopic ossification in the mouse knee joint. Clin Orthop Relat Res. 1981;218-223.

29. Sun Y, Mauerhan DR, Franklin AM, Norton J, Hanley Jr EN, Gruber HE. Phosphocitrate is potentially a disease-modifying drug for noncrystalassociated osteoarthritis. Biomed Res Int. 2013;2013:326267.

30. Sun Y, Roberts A, Mauerhan DR, Sun AR, Norton HJ, Hanley Jr EN. Biological activities of phosphocitrate: a potential meniscal protective agent. Biomed Res Int. 2013;2013:726581.

31. Sun Y, Mauerhan DR, Steuerwald NM, Ingram J, Kneisl JS, Hanley Jr EN. Expression of phosphocitrate-targeted genes in osteoarthritis menisci. Biomed Res Int. 2014;2014:210469.

32. Turhanen PA, Demadis KD, Peraniemi S, Vepsalainen JJ. A novel strategy for the preparation of naturally occuring phosphocitrate and its partially esterified derivatives. J Org Chem. 2007;72:1468-71.

33. Halverson PB, Garancis JC, McCarty DJ. Histopathological and ultrastructural studies of synovium in Milwaukee shoulder syndrome-a basic calcium phosphate crystal arthropathy. Ann Rheum Dis. 1984;43:734-41.

34. Reginato AJ, Schumacher HR. Synovial calcification in a patient with collagen-vascular disease: light and electron microscopic studies. J Rheumatol. 1977;4:261-71.

35. Jimenez PA, Glasson SS, Trubetskoy OV, Haimes HB. Spontaneous osteoarthritis in Dunkin Hartley guinea pigs: histologic, radiologic, and biochemical changes. Lab Anim Sci. 1997;47:598-601.

36. Meachim G. Light microscopy of Indian ink preparations of fibrillated cartilage. Ann Rheum Dis. 1972;31:457-64.

37. Huebner JL, Hanes MA, Beekman B, TeKoppele JM, Kraus VB. A comparative analysis of bone and cartilage metabolism in two strains of guinea-pig with varying degrees of naturally occurring osteoarthritis. Osteoarthritis Cartilage. 2002;10:758-67.

38. Sun Y, Mauerhan DR, Kneisl JS, Norton HJ, Zinchenko N, Ingram JA et al. Histologic evidence for collagen and proteoglycan changes in menisci of osteoarthritic patients. ACR conference. 2011

39. Kirsch T, Swoboda B, Nah H. Activation of annexin II and V expression, terminal differentiation, mineralization and apoptosis in human osteoarthritic cartilage. Osteoarthritis Cartilage. 2000;8:294-302.

40. Stockwell RA. Distribution of crystals in the superficial zone of elderly human articular cartilage of the femoral head in subcapital fracture. Ann Rheum Dis. 1990;49:231-5.

41. Nguyen C, Bazin D, Daudon M, Chatron-Colliet A, Hannouche D, Bianchi A, et al. Revisiting spatial distribution and biochemical composition of calciumcontaining crystals in human osteoarthritic articular cartilage. Arthritis Res Ther. 2013;15:R103.

42. McCarthy GM, Westfall PR, Masuda I, Christopherson PA, Cheung HS, Mitchell PG. Basic calcium phosphate crystals activate human osteoarthritic synovial fibroblasts and induce matrix metalloproteinase-13 (collagenase-3) in adult porcine articular chondrocytes. Ann Rheum Dis. 2001;60:399-406.

43. Sun Y, Mauerhan DR. Meniscal calcification, pathogenesis and implications. Curr Opin Rheumatol. 2012;24:152-7.

\section{Submit your next manuscript to BioMed Central and take full advantage of:}

- Convenient online submission

- Thorough peer review

- No space constraints or color figure charges

- Immediate publication on acceptance

- Inclusion in PubMed, CAS, Scopus and Google Scholar

- Research which is freely available for redistribution

Submit your manuscript at www.biomedcentral.com/submit 